\title{
Editorial 60
}

\author{
E. R. Scerri ${ }^{1}$
}

Published online: 21 August 2018

(c) Springer Nature B.V. 2018

The issue before you is the 60th since the birth of this journal 20 years ago. It opens with another wide-ranging article by Geoffrey Blumenthal and James Ladyman, who are based at the University of Bristol in the UK, and who breathe new life into several questions concerning the chemical revolution. To cite just one of the authors' conclusions, they consider the transition from a phlogiston-based chemistry to the new chemistry of Lavoisier to have been a fully rationally theory change.

Wojciech Grochala, from Warsaw in Poland, re-examines the question of the placement of helium in the periodic table. This is a timely piece given the approaching 150th anniversary of Mendeleev's discovery of the periodic system ${ }^{1}$ as well as the continued interest among periodic table scholars in the left-step periodic table as first suggested by Charles Janet. $^{2}$ In the article in this issue the author gives various kinds of arguments which lead him to conclude that helium should indeed be moved from group 18 to group 2 of the periodic table as Janet's table suggests.

Brad Wray is an American philosopher of science who is now based in Aarhus, Denmark. His article presents the rather intriguing proposal that the discovery of atomic number represented a scientific revolution in the sense of the writings of the later Kuhn. Wray has written extensively on Kuhn including a book length treatment of Kuhn's later turn towards an evolutionary account of theory change. On a personal note I would like to acknowledge that Wray's book ${ }^{3}$ was rather influential on my own writing concerning how theories change, evolutionary epistemology and Kuhn's position on these questions. ${ }^{4}$

Whereas the sociologist of science, Robert Merton, discussed multiple simultaneous independent discoveries (MID), Jeffrey Seeman, a US based chemist and historian of the

\footnotetext{
1 I take this opportunity to announce an international conference on the periodic table that is being coorganized by Mikhail Kurushkin, Philip Stewart and myself in St. Petersburg, Russia for July 26th-28th, 2019, in the UNESCO designated Year of the Periodic Table. http://mendeleev150.ifmo.ru//.

2 P.J. Stewart, Charles Janet: Unrecognized genius of the periodic system, Foundations of Chemistry 12 (1):5-15 (2010).

3 K.B. Wray, Kuhn's Evolutionary Social Epistemology, Cambridge University Press, Cambridge, 2014.

4 These ideas are explored in my recent book, E.R. Scerri, A Tale of Seven Scientists and A New Philosophy of Science, Oxford University Press, New York, 2016.
}

\section{E. R. Scerri}

scerri@chem.ucla.edu

1 Department of Chemistry and Biochemistry, UCLA, Los Angeles, CA 90095, USA 
subject, considers what he terms multiple simultaneous independent errors (MIE) and the possible connections between these two forms of scientific events with a rich set of examples drawn from twentieth century organic chemistry.

Two authors from Macedonia, Vladimir Petrusevki and Julijana Cvetcovik examine another perennial topic concerning the periodic table, namely the position of hydrogen. The authors review the five types of arguments that they have identified in connection with this question in an attempt to determine the optimal position for hydrogen.

The penultimate contribution comes from Buenos Aires in Argentina and consists of a spirited response from Sebastian Fortin, Olimpia Lombardi and Juan Camilo Gonzalez to an earlier article by Jeffrey Seeman, who made a much-needed plea for greater collaboration between historians and philosophers of chemistry and chemists. ${ }^{5}$

The issue closes with a review by KellyAnn Malinen and Cherif Matta, from Nova Scotia in Canada, of a mid-nineteenth century book that discusses the themes of climate change, the butterfly effect and chaotic dynamical systems long before these terms became popular in the twentieth century. 